\title{
Active Thermal Insulation of High-Temperature Surfaces of Technological Equipment Based on Packed Beds
}

\author{
Yu. S. Teplitsky ${ }^{1}$, E. A. Pitsukha ${ }^{2}$, V. A. Borodulya ${ }^{1} \&$ V. L. Malevich ${ }^{1}$ \\ ${ }^{1}$ A. V. Luikov Heat and Mass Transfer Institute, National Academy of Sciences of Belarus, Minsk, Belarus \\ ${ }^{2}$ Beloozersk Power Engineering Plant, Beloozersk, Belarus
}

Correspondence: E. A. Pitsukha, Beloozersk Power Engineering Plant, Beloozersk, Belarus. Tel: 81-037-516-436-3072. E-mail: pit.ea@mail.ru

Received: July 10, 2014 Accepted: July 24, 2014 Online Published: September 7, 2014

doi:10.5539/apr.v6n5p82 URL: http://dx.doi.org/10.5539/apr.v6n5p82

\begin{abstract}
Models of heat transfer in infiltrated packed beds of large low-heat conducting particles that are used as active thermal insulation of high-temperatures surfaces of technological equipment have been developed. A criterion of active thermal insulation involving main geometrical and thermal parameters of the infiltrated packed bed has been introduced. The effect of packed bed nonisothermicity and gas compressibility on the resistance of active thermal insulation has been investigated. An approximation dependence of the resistance of the bed on its geometrical, hydrodynamic, and thermal characteristics has been obtained. Cooling of a cap gas distributer via active insulation has been studied.
\end{abstract}

Keywords: thermal insulation, packed bed, models of heat transfer, high-temperatures surfaces

\section{Introduction}

Thermal insulation made of low-heat conducting packed material is widely used in practice. Infiltration of thermal insulation, as in the case of porous highly heat-conducting matrices of heat protecting coatings (Polyaev, Maiorov, \& Vasil'ev, 1988), substantially increases the intensity of heat and mass transfer processes and, thus, the efficiency of thermal insulation. In a number of industrial objects, e.g., heating furnaces, moderate- and small-power boilers, the efficiency of such thermal insulation that can be called active increases due to the fact that heated heat carrier (e.g., air) can be used in a technological process, thus improving its efficiency (heating of air before its supply to the furnace etc.). In such cases thermal insulation also plays a role of air heater.

\section{Main Schemes of Heat Carrier Motion in Active Thermal Insulation}

Thermal insulation in the form of an annular packed bed falls well in the arrangement of a cylindrical high-temperature chamber, e.g., cyclone-bed furnace. Figure 1 presents the main schemes of heat carrier motion, viz., radial (Figure 1a), longitudinal (Figure 1b), and tangential (Figure 1c).
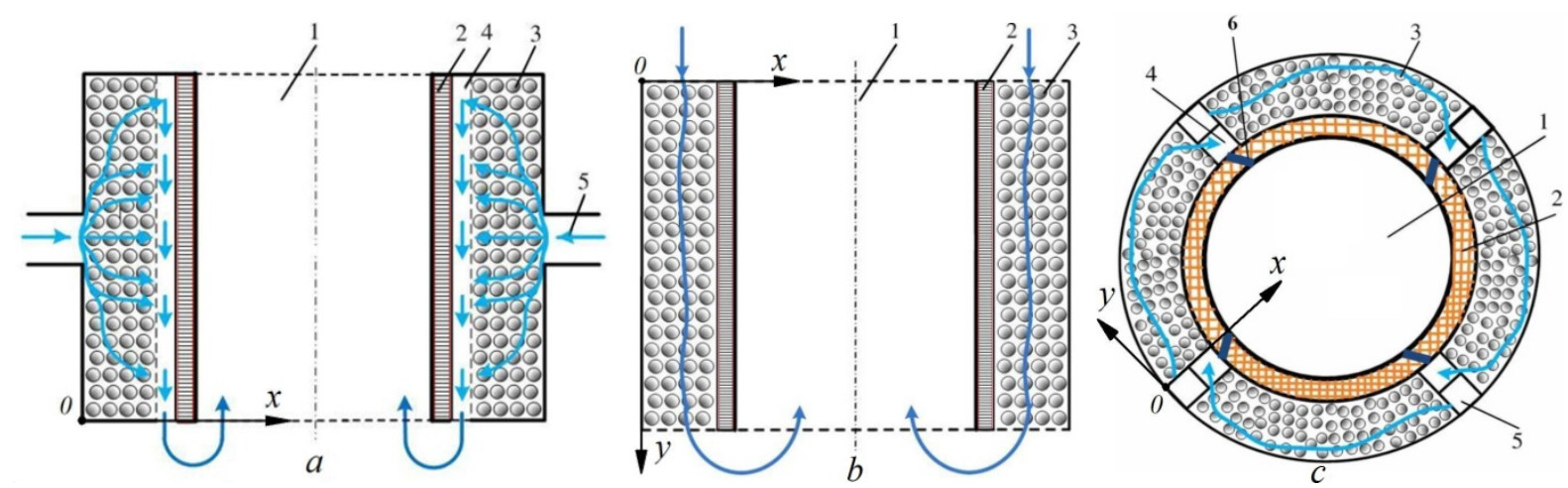

Figure 1. Main schemes of heat carrier motion in active thermal insulation: 1) combustion chamber; 2) lining of the combustion chamber; 3) packed bed; 4) channel of heated air; 5) channel of cold air; 6) tangential nozzles 


\section{Heat Transfer Models}

\subsection{Scheme of Figure 1 a}

Problem formulation. Taking into account a relatively small curvature of the furnace surface, in order to describe the process we use the two-temperature model for a plane bed where radiation heat transfer through the particle skeleton is disregarded:

$$
\begin{gathered}
C_{f} J_{f} \frac{d T_{f}}{d x}=\varepsilon \lambda_{f} \frac{d^{2} T_{f}}{d x^{2}}+\frac{6(1-\varepsilon) \alpha}{d}\left(T_{s}-T_{f}\right) \\
0=(1-\varepsilon) \lambda_{s} \frac{d^{2} T_{s}}{d x^{2}}+\frac{6(1-\varepsilon) \alpha}{d}\left(T_{f}-T_{s}\right)
\end{gathered}
$$

with the boundary conditions

$$
\begin{gathered}
x=0, \quad C_{f} J_{f}\left(T_{f}-T_{0}\right)=\varepsilon \lambda_{f} \frac{d T_{f}}{d x}+(1-\varepsilon) \lambda_{s} \frac{d T_{s}}{d x} \\
(1-\varepsilon) \lambda_{s} \frac{d T_{s}}{d x}=\alpha_{0}\left(T_{s}-T_{0}\right) \\
x=\delta, \quad \frac{d T_{f}}{d x}=0 ; \quad(1-\varepsilon) \lambda_{s} \frac{d T_{s}}{d x}=\sigma_{r}\left(T_{w}^{4}-T_{s}^{4}\right)
\end{gathered}
$$

The model parameters $\alpha, \alpha_{0}, \lambda_{f}, \lambda_{s}$, and $\sigma_{r}$ are calculated by the relations (Frank-Kamenetskii, 1967; Polezhaev, \& Selivestrov, 2002; Aerov, Todes, \& Narinskii, 1979; Teplitskii, \& Kovenskii, 2011; Borodulya, \& Kovenskii, 1983):

$$
\begin{gathered}
\alpha=1 /\left(\frac{d}{\lambda_{f}^{0}\left(2+1.8 \operatorname{Pr}^{1 / 3} \operatorname{Re}^{1 / 2}\right)}+\frac{3}{2} \frac{d}{\pi^{2} \lambda_{s}^{0}}\right) \\
S t_{0}=\frac{\alpha_{0}}{C_{f} J_{f}}=0.5 \operatorname{Re}^{-0.5} \operatorname{Pr}^{-0.6} \\
\lambda_{f}=\lambda_{f}^{0}+0.5 C_{f} J_{f} \frac{d}{\varepsilon} \\
\lambda_{s}=\frac{\lambda_{c}-\varepsilon \lambda_{f}^{0}}{1-\mathcal{E}} \\
\lambda_{c}=\lambda_{f}^{0}\left(\lambda_{s}^{0} / \lambda_{f}^{0}\right)^{(1-\varepsilon)\left(\lambda_{s}^{0} / \lambda_{f}^{0}\right)^{-0.06}} \\
\sigma_{r}=\sigma_{0} /\left(1 / \varepsilon_{e}+1 / \varepsilon_{w}-1\right) \\
\mathcal{E}_{e}=\varepsilon_{s}^{0.4}
\end{gathered}
$$

It should be noted that the second term in the denominator of (6) takes into account the effect of thermal resistance of a particle on interphase heat transfer (Frank-Kamenetskii, 1967).

To solve the problem posed we use the equation of the total heat balance

$$
\sigma_{r}\left(T_{w}^{4}-T_{s}^{4}(\delta)\right)=C_{f} J_{f}\left(T_{f}(\delta)-T_{0}\right)
$$

We determine the dimensionless relative temperatures of the phases in terms of the gas temperature at the outlet from the bed

$$
\theta_{s}=\frac{T_{s}-T_{0}}{T_{f}(\delta)-T_{0}} ; \theta_{f}=\frac{T_{f}-T_{0}}{T_{f}(\delta)-T_{0}}
$$

The initial problem (1)-(5) is solved at two stages: the first stage is the determination of relative temperatures $\theta_{s}(\xi)$ and $\theta_{f}(\xi)$; the second stage is the determination of the absolute temperatures of gas $T_{f}$ and particles $T_{s}$. In the dimensionless form the system of equations (1)-(5) for finding $\theta_{s}(\xi)$ and $\theta_{f}(\xi)$ is written with account for (13) as 


$$
\begin{gathered}
\frac{d \theta_{f}}{d \xi}=\frac{1}{P e_{f}} \frac{d^{2} \theta_{f}}{d \zeta^{2}}+\frac{1}{P e_{\alpha}}\left(\theta_{s}-\theta_{f}\right) \\
0=\frac{1}{P e_{s}} \frac{d^{2} \theta_{s}}{d \xi^{2}}+\frac{1}{P e_{\alpha}}\left(\theta_{f}-\theta_{s}\right) \\
\xi=0, \theta_{f}=\frac{1}{P e_{f}} \frac{d \theta_{f}}{d \xi}+\frac{1}{P e_{s}} \frac{d \theta_{s}}{d \xi} \\
\frac{1}{P e_{s}} \frac{d \theta_{s}}{d \xi}=S t_{0} \theta_{s} \\
\xi=1, \quad \frac{d \theta_{f}}{d \xi}=0, \quad \frac{1}{P e_{s}} \frac{d \theta_{s}}{d \xi}=1
\end{gathered}
$$

As is seen, the use of the balance relation (13) and determination of dimensionless temperatures in terms of $T_{f}(\delta)$ in the form of (14) allows substantial simplification of the form of the boundary condition for particles at the outlet from the bed. It should be noted that usually in modeling heat-protection elements it is assumed that $\lambda_{f}=0$ and conductive heat transfer is taken into account only in a porous highly heat conducting skeleton (Polyaev, Maiorov, $\&$ Vasil'ev, 1988). In our case, the skeleton thermal conductivity is small and the convective component $\lambda_{f}$ plays the main role (see (8)).

With due regard for the fact that the $P e_{f}, P e_{\alpha}$, and $S t_{0}$ numbers are the functions of $R e, P r$, and $d \delta$, the $P e_{s}$ number is a function of $R e, P r, d \delta$, and $\lambda_{c} / \lambda_{f}^{0}$, relative temperatures of the phases can be presented in the form of the following relations:

$$
\begin{gathered}
\theta_{s}(\xi)=f\left(\xi, \operatorname{Re}, \operatorname{Pr}, d / \delta, \lambda_{c} / \lambda_{f}^{0}\right) \\
\theta_{f}(\xi)=\varphi\left(\xi, \operatorname{Re}, \operatorname{Pr}, \frac{d}{\delta}, \frac{\lambda_{c}}{\lambda_{f}^{0}}\right)
\end{gathered}
$$

Solutions (15)-(19) for $\lambda_{s}^{0} / \lambda_{f}^{0}=44$ that are obtained based on the computer system of mathematical simulation Maple7 are given in Figure 2. In order to implement the problem formulated in the present work and to determine relations for calculation of absolute temperatures of the gas and particles at the outlet from the bed we should find the approximation of the dependence for calculation of relative temperatures of the gas and particles at the outlet from the bed. With account for slight variation of the $\operatorname{Pr}$ number within the temperature range $20-1000^{\circ} \mathrm{C}$, the functional relation $\theta_{s}(1)$ has the form

$$
\theta_{s}(1)=f\left(\operatorname{Re}, \frac{d}{\delta}, \frac{\lambda_{c}}{\lambda_{f}^{0}}\right)
$$

The obtained approximation of the function $f$ is

$$
\theta_{s}(1)=1+0.61 R e^{0.75}\left(\frac{\lambda_{c}}{\lambda_{f}^{0}}\right)^{-0.58}
$$

$\left(5.0 \leq R e \leq 1200 ; 2 \leq \frac{\lambda_{c}}{\lambda_{f}^{0}} \leq 15\right)$

In order to find the absolute quantities $T_{f}$ and $T_{s}$ we use condition (13) whose dimensionless form is as follows:

$$
\left(\theta_{s}^{\prime}(1)\right)^{4}+B o_{r} \theta_{f}^{\prime}(1)-\left(B o_{r}+\left(\theta_{w}^{\prime}\right)^{4}\right)=0
$$

The relation between $\theta_{s}^{\prime}(1)$ and $\theta_{f}^{\prime}(1)$ is 


$$
\theta_{f}^{\prime}(1)=1+\frac{\theta_{s}^{\prime}(1)-1}{\theta_{s}(1)}
$$

With account for (25) expression (24) will take the form of the fourth-power equation relative to $\theta_{s}^{\prime}(1)$

$$
\left(\theta_{S}^{\prime}(1)\right)^{4}+\frac{B o_{r}}{\theta_{S}(1)} \theta_{S}^{\prime}(1)-\left(\frac{B o_{r}}{\theta_{S}(1)}+\left(\theta_{W}^{\prime}\right)^{4}\right)=0
$$

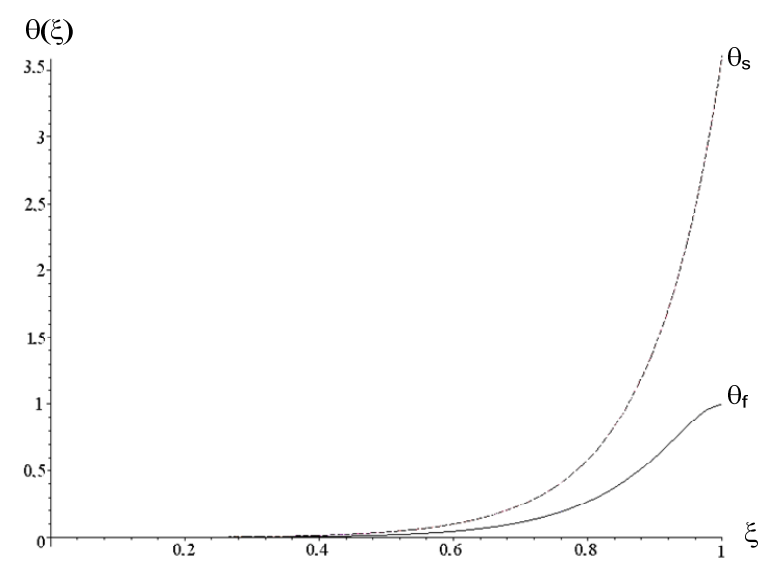

a)

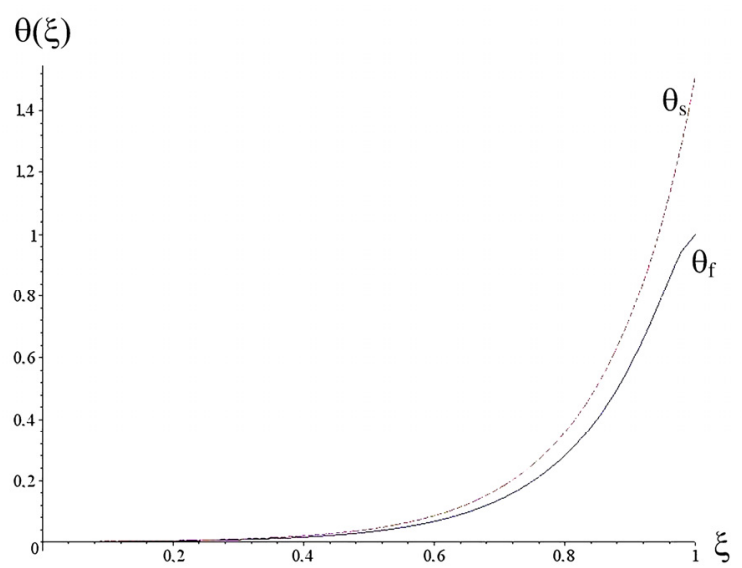

b)

Figure 2. Distribution of relative temperatures of the phases: a) $d=0.01 \mathrm{~m} ; \delta=0.1 \mathrm{~m} ; R e=30 ; b) d=0.001 \mathrm{~m} ; \delta$ $=0.02 \mathrm{~m} ; R e=5 . \quad \lambda_{s}^{0} / \lambda_{f}^{0}=44$.

As follows from (26) the temperature of particles at the outlet from the packed bed is determined by two dimensionless complexes $B o_{r} / \theta_{s}(1)$ and $\theta_{w}^{\prime}$ the first of which involves the quantity $\theta_{s}(1)$ found earlier. The results of numerical calculation of (26) are given in Figure 3. The following approximation of the solution of the problem under consideration is obtained;

$$
\theta_{s}^{\prime}(1)=\left(\theta_{w}^{\prime}\right)^{1 /\left(1+0.2\left(\theta_{w}^{\prime}\right)^{-4}\left(\frac{B o_{r}}{\theta_{s}(1)}\right)^{1.3}\right)}
$$

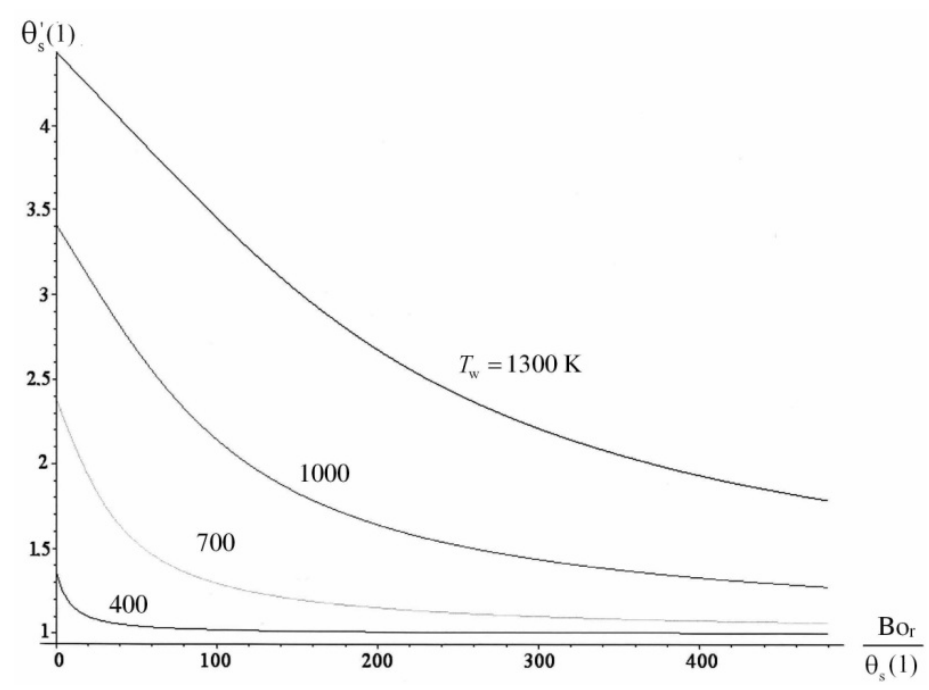

Figure 3. Dimensionless temperature of particles $\theta_{s}^{\prime}(1)$ as a function of the complex $B o_{r} / \theta_{s}(1)$ for different values of $T_{w}$ 
Function (27) satisfies obvious physical conditions at $J_{f}=0, \infty$ and describes the numerical solution of (26) within the ranges $1.4 \leq \theta_{w}^{\prime} \leq 4.3$ and $1 \leq B o_{r} / \theta_{s}(1) \leq 500$ with an error not higher than $2 \%$. With account for $(25)$ and (27) for $\theta_{f}^{\prime}(1)$ we have the formula

$$
\left.\theta_{\mathrm{f}}^{\prime}(1)=1+\frac{\left(\theta_{w}^{\prime}\right)}{\theta_{s}(1)}-1 /\left(1+0.2\left(\theta_{w}^{\prime}\right)^{-4}\left(\frac{B o_{r}}{\theta_{s}(1)}\right)^{1.3}\right)\right)
$$

where $\theta_{s}(1)$ is calculated by (23).
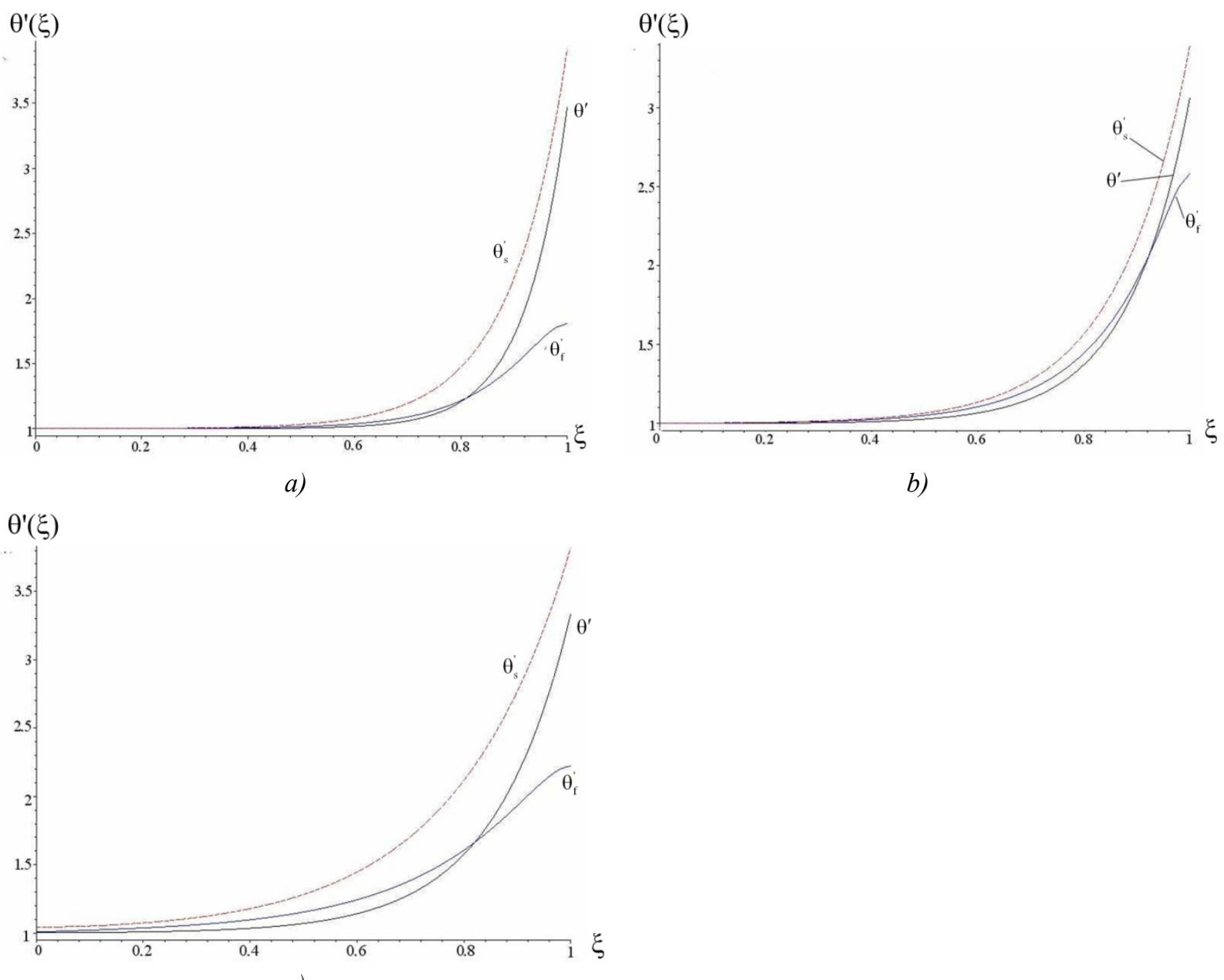

c)

Figure 4. Distribution of dimensionless temperatures of the phases: $\mathcal{E}_{w}=0.8 ; \mathcal{E}_{s}=0.6$ a) $d=0.01 \mathrm{~m} ; \delta=0.1 \mathrm{~m}$; $\left.\left.R e=30 ; \lambda_{s}^{0} / \lambda_{f}^{0}=44 ; b\right) d=0.001 \mathrm{~m} ; \delta=0.02 \mathrm{~m} ; \operatorname{Re}=5 ; \quad \lambda_{s}^{0} / \lambda_{f}^{0}=44 ; c\right) d=0.01 \mathrm{~m} ; \quad \delta=0.1 \mathrm{~m} ; \operatorname{Re}=30 ;$ $\lambda_{s}^{0} / \lambda_{f}^{0}=2300 ; T_{\mathrm{w}}=1200 \mathrm{~K}$

Figure 4 shows the profiles of temperatures $\theta_{s}^{\prime}(\xi)$ and $\theta_{f}^{\prime}(\xi)$ calculated based on the solutions of (15)-(19) and (26) with account for (25). As is seen, the temperatures $\theta_{s}^{\prime}(0)$ and $\theta_{f}^{\prime}(0)$, even in the case of highly heat-conducting material (Figure 4c), slightly differ from unity, which indicates practical equality of $T_{0}$ to the temperature of the outer surface of thermal insulation. The same figure shows the profiles of the temperature $\theta^{\prime}(\xi)$ constructed by the dependence 


$$
\left.\theta^{\prime}(\xi)=1+\left(\theta_{w}^{\prime}\right)^{\left(1 /\left(1+0.45\left(\theta_{w}^{\prime}\right)^{-4}\left(B o_{r}\right)^{1.16}\right)\right.}-1\right) \exp (\operatorname{Pe}(\xi-1))
$$

$\left(1.4 \leq \theta_{w}^{\prime} \leq 4.3 ; 100 \leq B o_{r} \leq 4000\right)$,

obtained as a result of a similar solution for a one-temperature model (for which $\theta_{s}(1) \equiv 1$ ):

$$
\begin{gathered}
C_{f} J_{f} \frac{d T}{d x}=\lambda \frac{d^{2} T}{d x^{2}} \\
x=0, \quad C_{f} J_{f}\left(T-T_{0}\right)=\lambda \frac{d T}{d x} \\
x=\delta, \quad \lambda \frac{d T}{d x}=\sigma_{r}\left(T_{\mathrm{w}}^{4}-T^{4}\right)=C_{f} J_{f}\left(T-T_{0}\right) .
\end{gathered}
$$

As is seen, the temperatures $\theta_{\mathrm{f}}^{\prime}(\xi)$ and $\theta^{\prime}(\xi)$ are rather close to each other every where except for the outlet zone. This is explained, on the one hand, by the proximity of the equations for $\theta_{\mathrm{f}}^{\prime}$ and $\theta^{\prime}$, and, on the other hand, by the difference of the boundary conditions (5) and (32).

\subsection{Schemes of Figures $1 b$ and $1 c$}

Problem formulation. Taking into account a relatively small curvature of the furnace surface, we use, for description of the steady-state heat transfer in the lining and the packed bed, a simplified model of plane beds and the corresponding system of equations:

$$
\begin{gathered}
0=\lambda_{m}\left(\frac{\partial^{2} T_{m}}{\partial x^{2}}+\frac{\partial^{2} T_{m}}{\partial y^{2}}\right), \quad 0 \leq x \leq \delta_{m} \\
C_{f} J_{f} \frac{\partial T}{\partial y}=\frac{\partial}{\partial x}\left(\lambda_{x} \frac{\partial T}{\partial x}\right)+\frac{\partial}{\partial y}\left(\lambda_{y} \frac{\partial T}{\partial y}\right), \quad \delta_{m} \leq x \leq \delta_{m}+\delta
\end{gathered}
$$

with the boundary conditions

$$
\begin{gathered}
x=0, \quad-\lambda_{m} \frac{\partial T_{m}}{\partial x}=\alpha_{\infty}\left(T_{\infty}-T_{m}\right) \\
x=\delta_{m}, \quad-\lambda_{m} \frac{\partial T_{m}}{\partial x}=\alpha_{w}\left(T_{w}-T\right)+\sigma_{r}\left(T_{w}^{4}-T^{4}\right) \\
x=\delta_{m}+\delta, \quad \frac{\partial T}{\partial x}=0 \\
y=0, \quad \frac{\partial T_{m}}{\partial y}=0 ; \quad C_{f} J_{f} T_{0}=C_{f} J_{f} T-\lambda_{y} \frac{\partial T}{\partial y} \\
y=L, \frac{\partial T_{m}}{\partial y}=\frac{\partial T}{\partial y}=0 .
\end{gathered}
$$

The model parameters are (Aerov, Todes, \& Narinskii, 1979; Teplitskii, \& Kovenskii, 2011)

$$
\begin{gathered}
\lambda_{x}=\lambda_{c}+0.1 C_{f} J_{f} d \\
\lambda_{y}=\lambda_{c}+0.5 C_{f} J_{f} d \\
\alpha_{w}=\frac{10}{d}\left(\lambda_{f}^{0}+0.0061 C_{f} J_{f} d\right)
\end{gathered}
$$

The heat transfer coefficient $\alpha_{\infty}$ is determined by the standard method of thermal calculations of boilers (Anonymous, 1998). The quantities $\lambda_{c}$ and $\sigma_{r}$ are presented by (10)-(12). 
Temperature fields in the lining and the packed bed were calculated by Fluent. An example of solution of the thermal problem for thermal insulation of the boiler with a power of $0.5 \mathrm{MW}$ is shown in Figure $5 \mathrm{a}$. As is seen, the air filtration through the insulation layer leads to the existence of a rather vast area of low temperatures near its outer surface. This indicates that an infiltrated packed bed, though being rather thin $(\delta=0.085 \mathrm{~m})$, exhibits good thermo-insulating properties.

Figure $5 \mathrm{~b}$ show similar results obtained from the problem solution without account for the radiation flux in (36). As is seen, the difference between the results presented in Figure 5a and 5b is not substantial, which is likely related to the effect of large thermal resistance of the lining layer with $\delta_{m}=0.11 \mathrm{~m}$ on this flow. The result obtained formed the basis for more thorough analysis of thermal mechanics of active thermal insulation with the effect of radiation on it being ignored.
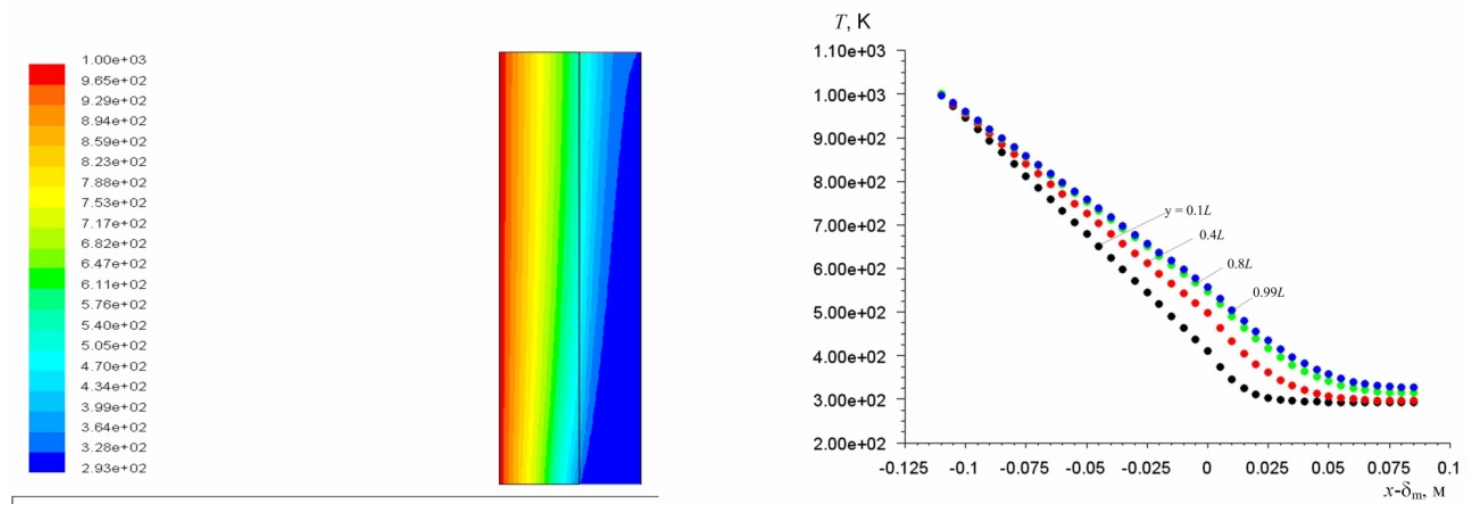

a)
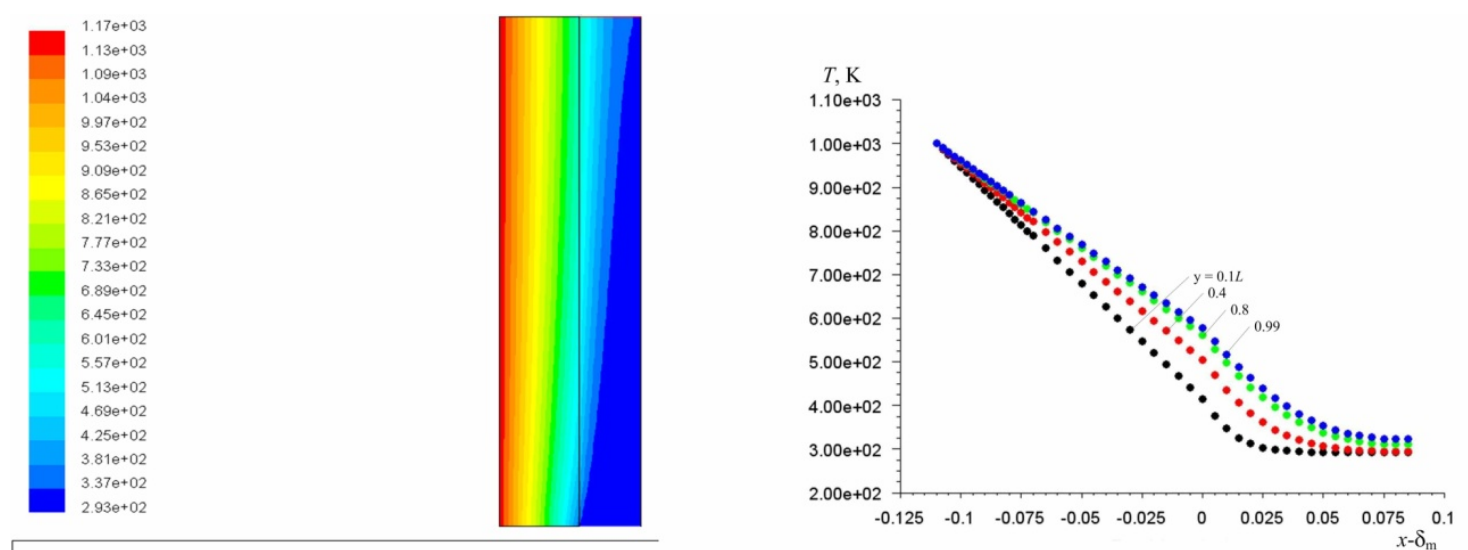

b)

Figure 5. Temperature distribution over the volume of thermal insulation $W=0.5 \mathrm{MW} . \delta_{m}=0.11 \mathrm{~m} ; \delta=0.085 \mathrm{~m} ; L$ $\left.=0.79 \mathrm{~m} ; J_{\mathrm{f}}=0.5 \mathrm{~kg} /\left(\mathrm{m}^{2} \mathrm{~s}\right) ; T_{0}=293 \mathrm{~K} ; T_{\infty}=1173 \mathrm{~K} ; \lambda_{m}=1.25 \mathrm{~W} /(\mathrm{m} \mathrm{K}) ; d=0.02 \mathrm{~m}: a\right)$ with and $\left.b\right)$ without account for radiative transfer in the cyclone-bed furnace of the boiler

In order to obtain an analytical solution convenient for analysis, we considered a simplified version of (33)-(39) where a one-zone problem of heat conduction at large Peclet numbers $P e_{y}=C_{f} J_{f} L / \lambda_{y} \geq 10$ is formulated:

$$
\begin{gathered}
\frac{\partial \bar{\theta}}{\partial \eta}=\frac{1}{P e_{a c t}} \frac{\partial^{2} \bar{\theta}}{\partial \xi^{2}} \\
\xi=0,-\frac{\partial \bar{\theta}}{\partial \xi}=B i(1-\bar{\theta}) \\
\xi=1, \frac{\partial \bar{\theta}}{\partial \xi}=0 \\
\eta=0, \bar{\theta}=0 .
\end{gathered}
$$


Solution (43)-(46) is the known solution (Luikov, 1967) of nonstationary problem of plate heating at the boundary conditions of III kind:

$$
\bar{\theta}\left(\xi, \frac{\eta}{P e_{a c t}}, B i\right)=1-\sum_{n=1}^{\infty} A_{n} \cos \mu_{n}(1-\xi) \exp \left(-\mu_{n}^{2} \frac{\eta}{P e_{a c t}}\right)
$$

The expressions for $A_{n}$ and $\mu_{n}$ are given in Luikov (1967).

The number $P e_{a c t}=\frac{C_{f} J_{f} \delta^{2}}{L \lambda_{x}}$ includes the main geometric, hydrodynamic, and thermal parameters of the infiltrated packed bed. By virtue of this, the $P e_{a c t}$ number may be termed the criterion of active thermal insulation. Figures 6 and 7 show the temperature distributions over the thickness of thermal insulation at different values of $\eta / P e_{\text {act }}$ (different lengths of a packed bed). As is seen, at $B i \geq 5$ the dependence of temperature fields on $B i$ becomes weaker. This also refers to the temperatures at the outer boundary of the bed which determine thermo-insulating properties of the system. The following generalized dependences are obtained for their calculation on the basis of (47):

$$
\begin{aligned}
& \bar{\theta}\left(1, \frac{\eta}{P e_{a c t}}, B i\right)=1-\exp \left(-0.6\left(\frac{\eta}{P e_{a c t}}\right)^{1.8} B i^{0.66}\right),\left(0.2 \leq B i \leq 5 ; 0.1 \leq \frac{\eta}{P e_{a c t}} \leq 1\right) \\
& \bar{\theta}\left(1, \frac{\eta}{P e_{a c t}}, B i\right)=1-\exp \left(-1.5\left(\frac{\eta}{P e_{a c t}}\right)^{1.8} B i^{0.08}\right),\left(5 \leq B i \leq 50 ; 0.1 \leq \frac{\eta}{P e_{a c t}} \leq 1\right)
\end{aligned}
$$

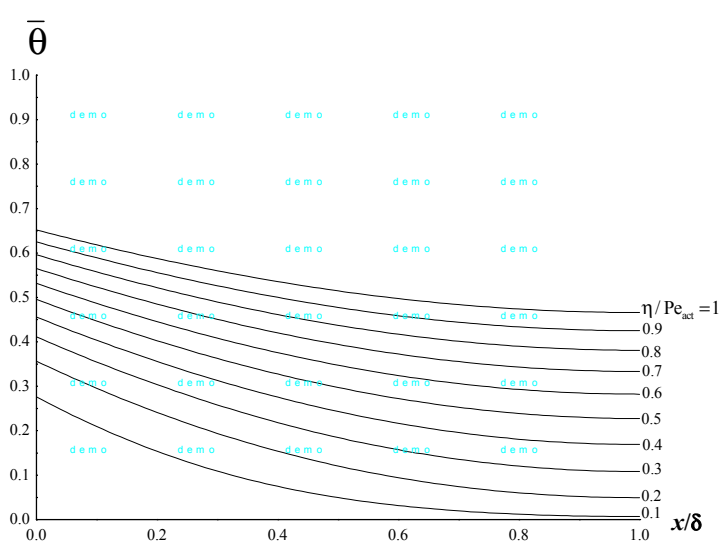

a)

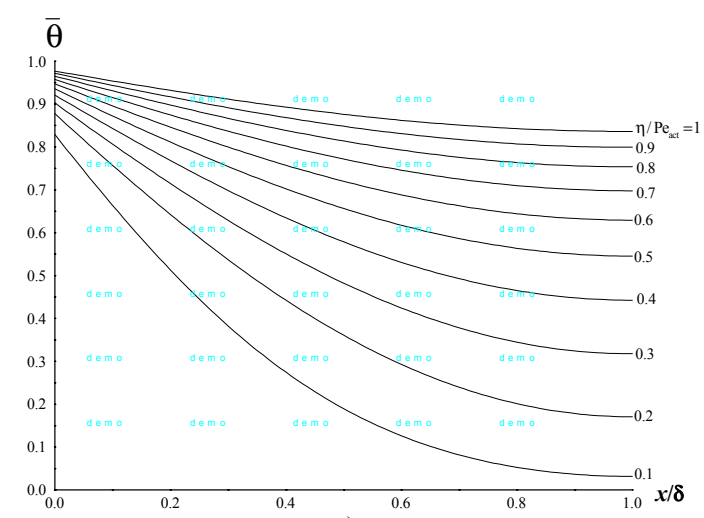

c)

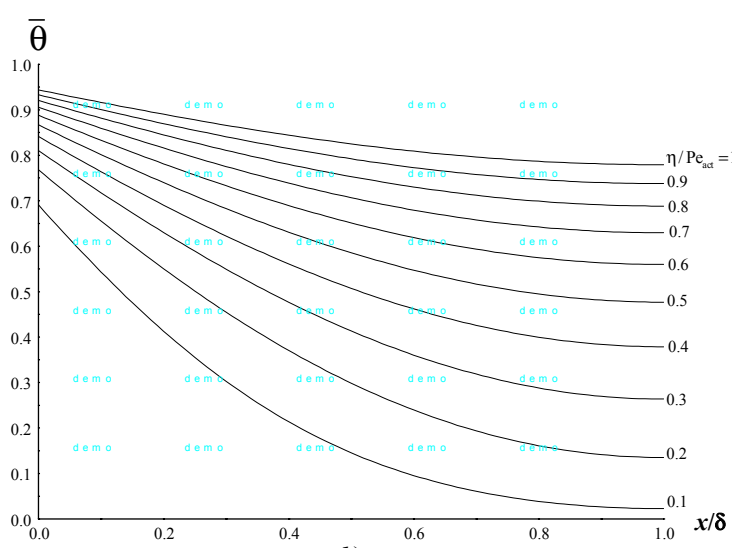

b)

Figure 6. Distribution of the dimensionless temperature over the bed thickness: $a, b, c) B i=1,5,10$ 


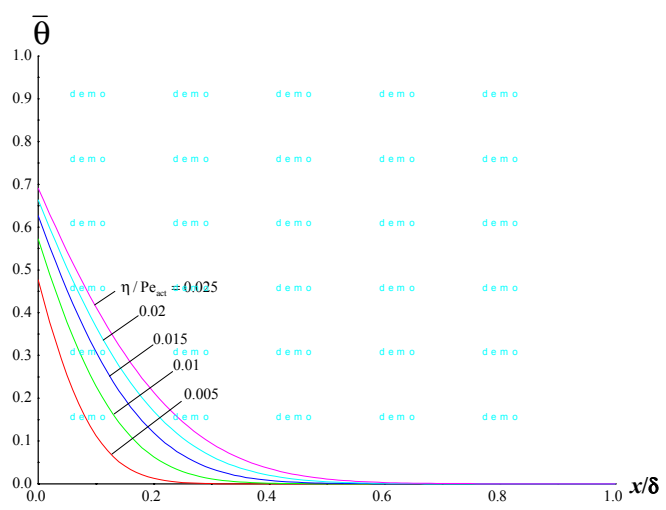

Figure 7. Distribution of the dimensionless temperature over the bed thickness at small values of $\eta / P e_{a c t} . B i=10$

We consider another important property of active thermal insulation, i.e., heating of a heat carrier. To calculate it, we determine, based on (47), the temperature that is mean over the cross section $y=$ const:

$$
\langle\bar{\theta}\rangle\left(\frac{\eta}{P e_{a c t}}, B i\right)=\int_{0}^{1} \bar{\theta}\left(\xi, \frac{\eta}{P e_{a c t}}, B i\right) d \xi=1-\frac{1}{B i} \sum_{n=1}^{\infty} A_{n} \frac{\sin ^{2} \mu_{n}}{\cos \mu_{n}} \exp \left(-\mu_{n}^{2} \frac{\eta}{P e_{a c t}}\right) .
$$

Calculation of the quantities $\langle\bar{\theta}\rangle\left(\frac{\eta}{P e_{a c t}}, B i\right)$ is given in Figure8. A simple analytical presentation of these results is obtained in the form of generalized dependences similar to (48) and (49):

$$
\begin{gathered}
\bar{\theta}\left(\frac{\eta}{P e_{a c t}}, B i\right)=1-\exp \left(-0.65\left(\frac{\eta}{P e_{a c t}}\right)^{0.9} B i^{0.66}\right),\left(0.2 \leq B i \leq 5 ; 0.1 \leq \frac{\eta}{P e_{a c t}} \leq 1\right) \\
\bar{\theta}\left(\frac{\eta}{P e_{a c t}}, B i\right)=1-\exp \left(-1.9\left(\frac{\eta}{P e_{a c t}}\right)^{0.9} B i^{0.08}\right), \quad\left(5 \leq B i \leq 50 ; 0.1 \leq \frac{\eta}{P e_{a c t}} \leq 1\right)
\end{gathered}
$$

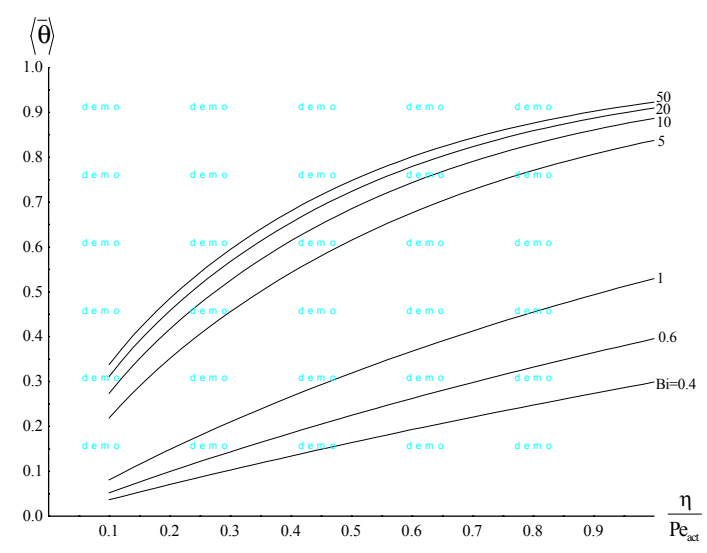

Figure 8. Distribution of the mean dimensionless temperature of the bed along its length at different values of the Biot number 


\section{Calculation of Active Thermal Insulation of the Vortex Furnace of the Water Boiler With Power 0.5 MW}

The following parameters of thermal insulation are adopted (Figure 1c):

$R_{1}=0.545 \mathrm{~m} ; R_{2}=0.46 \mathrm{~m} ; n=4$ (number of nozzles); $\delta_{m}=0.11 \mathrm{~m} ; \lambda_{m}=1.25 \mathrm{~W} /(\mathrm{m} \cdot \mathrm{K})$ (firebrick); $d=0.02 \mathrm{~m} ; T_{0}=$ $20^{\circ} \mathrm{C} ; T_{\infty}=900^{\circ} \mathrm{C} ; J_{f}=0.5 \mathrm{~kg} /\left(\mathrm{m}^{2} \cdot \mathrm{s}\right) ; L=\pi\left(R_{1}+R_{2}\right) / n=0.79 \mathrm{~m} ; \delta=R_{1}-R_{2} ; \lambda_{s}^{0}=0.24 \mathrm{~W} /(\mathrm{m} \cdot \mathrm{K})$ (aggloporite).

For the quantities $B i$ and $P e_{a c t}$ we obtained: $B i=0.58 ; P e_{a c t}=3.33$. The results of calculation of the temperature distribution on the outer boundary of thermal insulation $T(\delta, y)$ and the mean temperature of heat carrier along the length of the packed bed $\langle T\rangle(y)$ by (48) and (51) are listed in Table 1.

Table 1. The temperature distribution in thermal insulation

\begin{tabular}{cccccc}
\hline$\frac{\eta}{P e_{a c t}}$ & $\bar{\theta}\left(1, \frac{\eta}{P e_{a c t}}, B i\right)$ & $\langle\bar{\theta}\rangle\left(\frac{\eta}{P e_{a c t}}, B i\right)$ & $y, \mathrm{~m}$ & $T(\delta, y),{ }^{\circ} \mathrm{C}$ & $\langle T\rangle(y),{ }^{\circ} \mathrm{C}$ \\
\hline 0.1 & 0.006 & 0.05 & 0.26 & 26 & 64 \\
0.2 & 0.023 & 0.10 & 0.52 & 40 & 109 \\
0.3 & 0.047 & 0.14 & 0.79 & 61 & 143 \\
\hline
\end{tabular}

As is seen, the temperature of the outer side of thermal insulation is low and changes within the range $20-60^{\circ} \mathrm{C}$. At the same time, heating of the heat carrier (air) at the outlet from the bed (at $\eta=1$ ) is substantial and amount to $123^{\circ} \mathrm{C}$.

\subsection{Thermal Conditions of the Cap Gas Distributer With Active Thermal Insulation}

Problem formulation. We study thermal conditions of a cap gas distributer with active thermal insulation in the fluidized bed furnace (Figure 9a). As is known (Kunii, \& Levenspiel, 1976), this type of gas distributers is widely used in organization of different technological processes in large-scale equipment with fluidized bed. In this case, the role of active insulation is to cool the upper gas-tight wall of lattice 4 and to cool primary air coming into furnace 1 through caps 3 .

Figure $9 b$ shows a typical part of the gas distributer and a qualitative character of air streamlines filtered through a packed bed. As is seen, the flow patters is rather complex which makes simulation of the process of convective heat transfer difficult. In this connection, a simplified thermal scheme that takes into account radiative heat transfer and conductive-convective heat exchange between the gas-tight plate of the gas distributer and the packed bed was adopted.

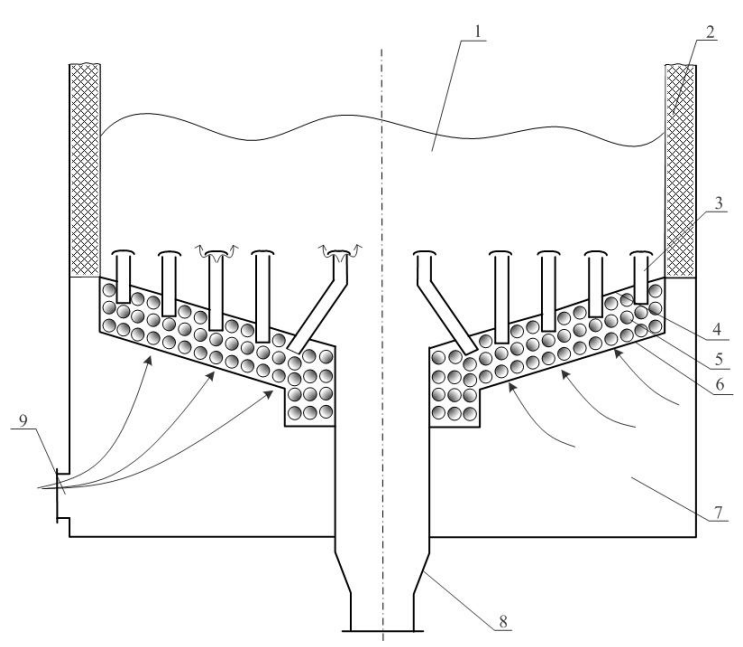

a)

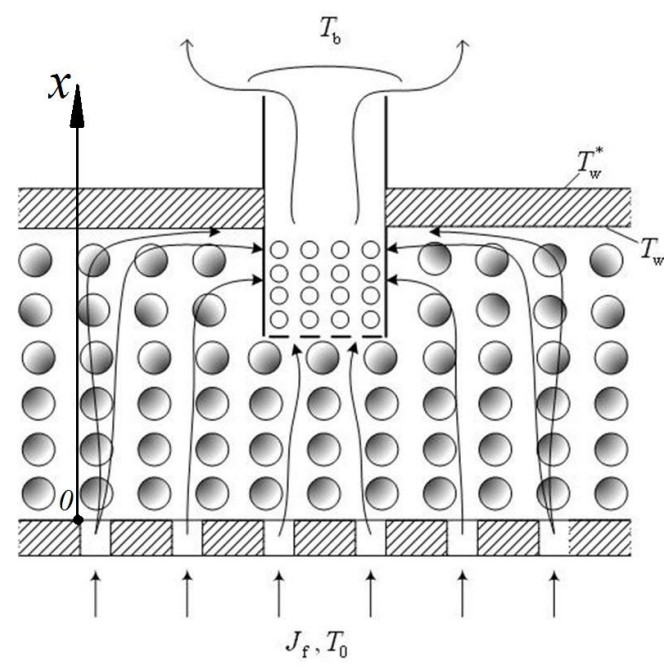

b)

Figure 9. a) A cap gas distributer with active thermal insulation in a fluidized bed: 1) fluidized bed; 2) furnace

lining; 3) cap; 4) upper gas-tight plate of the distributer; 5) packed material; 6) lower perforated wall; 7) subdistributer chamber; 8) discharge branch pipe; 9) air supply; b) part of a gas distributer with air streamlines 
The main assumptions are as follows:

- a one-dimensional model of heat conduction of the infiltrated packed bed of thermal insulation is considered;

- the difference between the temperatures of the packed bed phases is neglected which is justifiable at rather high air velocities;

- the effect of the bending of air streamlines near the gas-tight wall of the gas distributer (Figure 9b) is taken into account proceeding from the formulation of the regularities of conductive-convective heat transfer in this region based on the wall coefficient of heat transfer $\alpha \mathrm{w}$ that is introduced under the conditions of heat carrier motion along the heat transfer surface (Teplitskii, \& Kovenskii, 2011; Dekhtyar, Sikovskii, Gorin, \& Mukhin, 2002) (Equation (42)).

The system of equation that describes air heating in filtration through the packed bed of thermal insulation with a thickness $\delta$ has the form

$$
\begin{gathered}
C_{f} J_{f} \frac{d T}{d x}=\lambda \frac{d^{2} T}{d x^{2}}, \\
x=0, C_{f} J_{f} T-\lambda \frac{d T}{d x}=C_{f} J_{f} T_{0}, \\
x=\delta, \lambda \frac{d T}{d x}=\sigma_{r}\left(T_{w}^{4}-T^{4}\right)+\alpha_{w}\left(T_{w}-T\right) .
\end{gathered}
$$

The parameters of model (53)-(55) are found in (Aerov, Todes, \& Narinskii, 1979; Teplitskii, \& Kovenskii, 2011):

$$
\begin{gathered}
\lambda=\lambda_{c}+0.5 C_{f} J_{f} d, \\
\lambda_{f}^{0}=0.00021 T_{*}^{0.84} .
\end{gathered}
$$

The characteristic temperature $T_{*}$ involved in (57) was taken equal to $\left(T(\delta)+T_{0}\right) / 2$, when $\lambda_{c}$ is determined by (10), and to $T_{*}=T_{w}$ when $\alpha_{w}$ is determined by (42).

We write Equations (53)-(55) in the dimensionless form:

$$
\begin{gathered}
\frac{d \theta^{\prime}}{d \xi}=\frac{1}{P e} \frac{d^{2} \theta^{\prime}}{d \xi^{2}}, \\
\xi=0, \theta^{\prime}=\frac{1}{P e} \frac{d \theta^{\prime}}{d \xi}, \\
\xi=1, \frac{d \theta^{\prime}}{d \xi}=S k\left(\left(\theta_{w}^{\prime}\right)^{4}-\left(\theta^{\prime}\right)^{4}\right)+B i_{w}\left(\theta_{w}^{\prime}-\theta^{\prime}\right),
\end{gathered}
$$

A specific character of this formulation is that the temperature $T_{w}$, involved in the boundary condition (55) or (60) at $x=\delta$ is the unknown quantity (only the fluidized bed temperature $T_{b}$ is known a priori, Figure $9 b$ ). By virtue of this, in order to calculate the thermal state of a gas distributer with a bed of active thermal insulation one should use the method of successive approximations.

Solution (58)-(60) has the form

$$
\theta^{\prime}(\xi)=1+C e^{P e \xi}
$$

where the coefficient $C$ is determined from the solution of the fourth-power equation which follows from (61):

$$
C P e e^{P e}=S k\left(\left(\theta_{w}^{\prime}\right)^{4}-\left(1+C e^{P e}\right)^{4}\right)+B i_{w}\left(\theta_{w}^{\prime}-\left(1+C e^{P e}\right)\right) .
$$

Since the temperature of the air discharging from the packed bed $T(\delta)$ that specifies heating of the air injected into the furnace is the main quantity to be determined, it is more convenient to write (62) in an equivalent form:

$$
\theta^{\prime}(\xi)=1+\left(\theta^{\prime}(1)-1\right) e^{P e(\xi-1)} .
$$

The quantity $T(\delta)$ can be found independently from the balance equation that determines the density of the heat flux through the gas distributer $q$ :

$$
q=C_{f} J_{f}\left(T(\delta)-T_{0}\right)=\sigma_{r}\left(T_{w}^{4}-T^{4}(\delta)\right)+\alpha_{w}\left(T_{w}-T(\delta)\right)
$$


The dimensionless form of $(64)$ is

$$
\theta^{\prime}(1)-1=\frac{1}{B o_{r}}\left(\left(\theta_{w}^{\prime}\right)^{4}-\left(\theta^{\prime}\right)^{4}(1)\right)+S t_{w}\left(\theta_{w}^{\prime}-\theta^{\prime}(1)\right) .
$$

Calculation of $\theta^{\prime}(1)$ by (65) is given in Figure 10 for the specified values of $\theta_{w}^{\prime}=2,3$, and 4 . We took into account that the Bo and $S t_{w}$ numbers are not independent and both are determined by the air mass flow rate $J_{f}$.

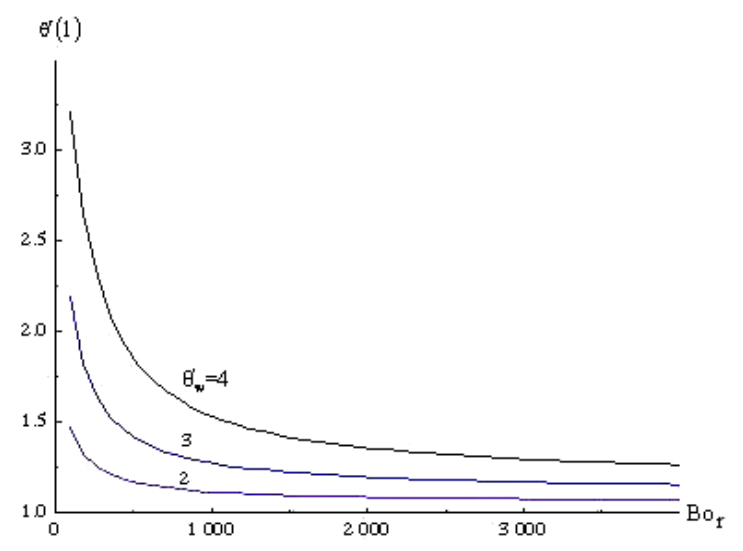

Figure 10. Dimensionless outlet air temperature $\theta^{\prime}(1)$ as a function of the reduced Boltzmann number (calculated by Equation (65))

As is seen, at elevated values of $B o_{r}$ (elevated air flow rates $\left.J_{f}\right) T(\delta)$ begins to change rather weakly. This is, likely, the consequence of the existence of two tendencies. On the one hand, as $J_{f}$ increases, the air passes through a packed bed quicker and thus is less heated. On the other hand, as $T(\delta)$ decreases, the heat flux from the fluidized bed $q$ (the right-hand side of (65)) increases, thus leading to an increase in $T(\delta)$.

In order to calculate the acting temperature mode of the system 'active thermal insulation-upper gas-tight wall of the lattice' at the given temperature of the fluidized bed $T_{b}$ we used the method of successive approximations. First we write the expression for $T_{b}$ on the basis of the equation for the heat-flux density with account for (65)

$$
T_{b}=T_{w}+C_{f} J_{f}\left(T(\delta)-T_{0}\right)\left(\frac{1}{\alpha_{b}}+\frac{\delta_{m}^{*}}{\lambda_{m}^{*}}\right)
$$

The temperature $T_{w}^{*}$ (Figure $9 b$ ) is determined by a similar formula

$$
T_{w}^{*}=T_{w}+C_{f} J_{f}\left(T(\delta)-T_{0}\right) \frac{\delta_{m}}{\lambda_{m}} .
$$

The coefficient of heat exchange between the fluidized bed and the gas-tight surface of the lattice $\alpha_{b}$ is, as is known (Kunii, \& Levenspiel, 1976; Baskakov, Matsnev, \& Raspopov, 1996), a rather complex function of a large number of parameters of the fluidized bed itself and of the heat transfer surface. But, as is shown in (Baskakov, Matsnev, \& Raspopov, 1996), on operation of furnaces under the conditions of developed fluidization of large particles $\left(d_{b}=1-3 \mathrm{~mm}\right)$ at $T_{b}=850^{\circ} \mathrm{C}$ with an error not higher than $10 \%$ it is assumed to take $\alpha_{b}$ constant and equal to $250 \mathrm{~W} /\left(\mathrm{m}^{2} \mathrm{~K}\right)$.

The schematic diagram of the calculation of temperatures $T(\delta), T_{w}$, and $T_{w}^{*}$ is given in Figure 11. 


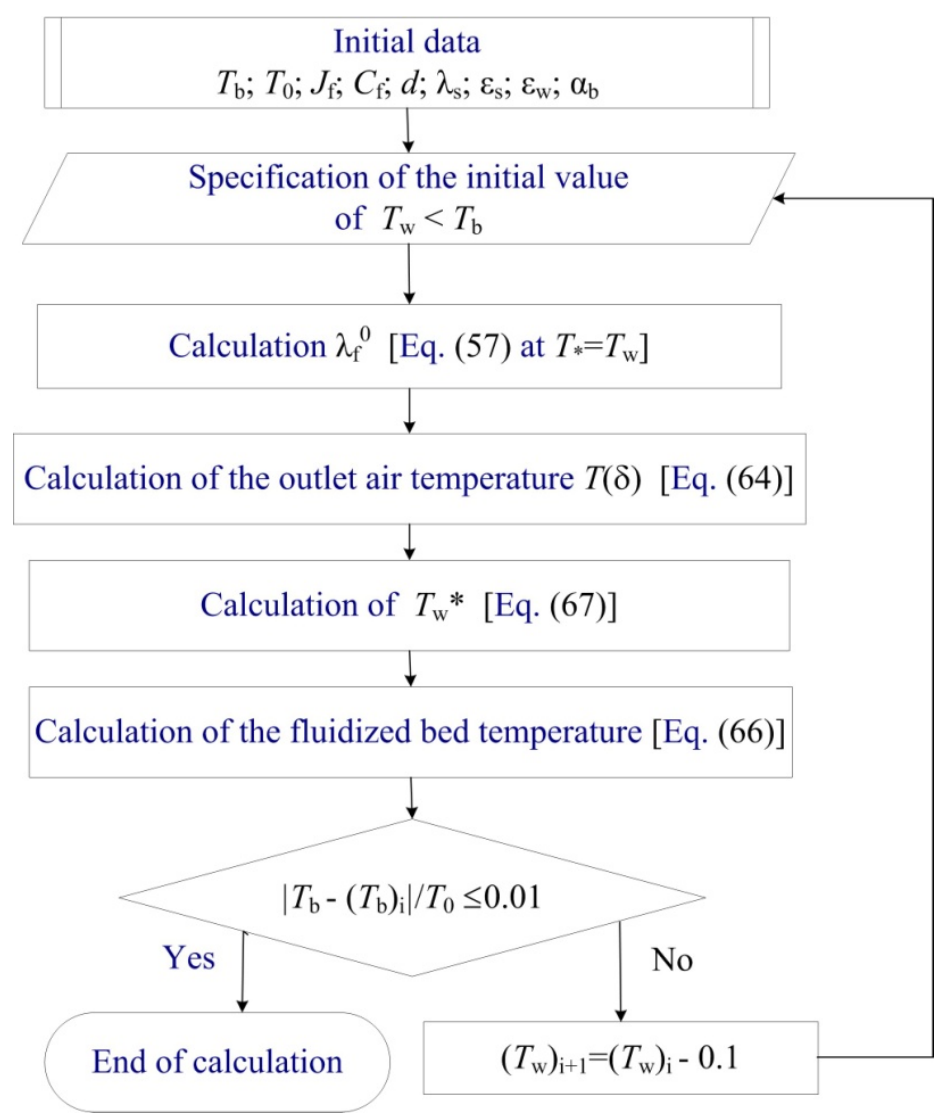

Figure 11. Schematic diagram of the calculation of temperatures $T(\delta), T_{w}$, and $T_{w}^{*}$

Figure 12 presents the results of the calculation of $T(\delta)$ and $T_{w}$ depending on the value of the air mass flow rate. As is seen, using of acting thermal insulation allows rather effective cooling of the upper gas-tight plate of the lattice $\left(T_{b}-T_{w}\right)=200-450^{\circ} \mathrm{C}$. It should be noted that the temperature difference along the plate $T_{w}^{*}-T_{w}$, determined by Equation (67), does not exceed several dozens of degrees. Heating of air discharging from the packed bed greatly depends on the value of $J_{f}$ and amounts to $30-300^{\circ} \mathrm{C}$. In Figure 13, the profile of temperatures in the insulation which is built by Equation (63) for different values of $J_{f}$ is shown. As is seen, the bed temperature begins to increase substantially at $\xi>0.7$.

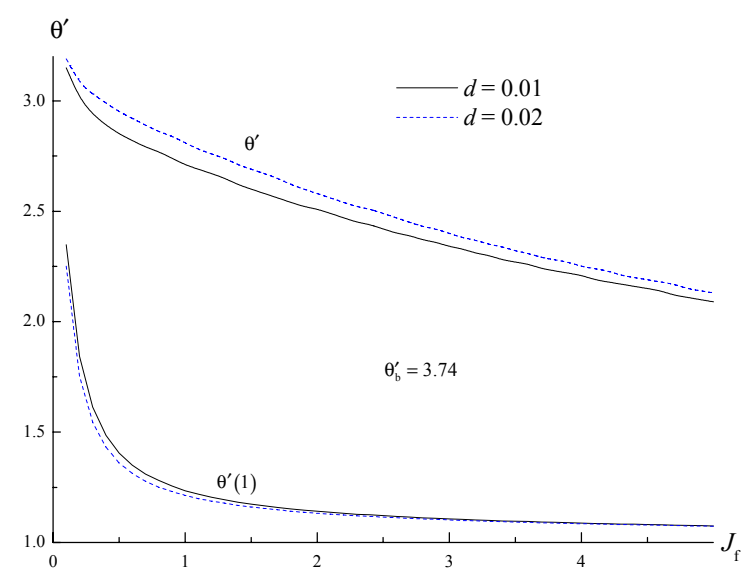

Figure 12. The air outlet temperature $\theta^{\prime}(1)$ as a function of the mass flow rate of air $\theta_{b}^{\prime}=3.74, J_{f}\left[\mathrm{~kg} /\left(\mathrm{m}^{2} \mathrm{~s}\right)\right], d, \mathrm{~m}$ 


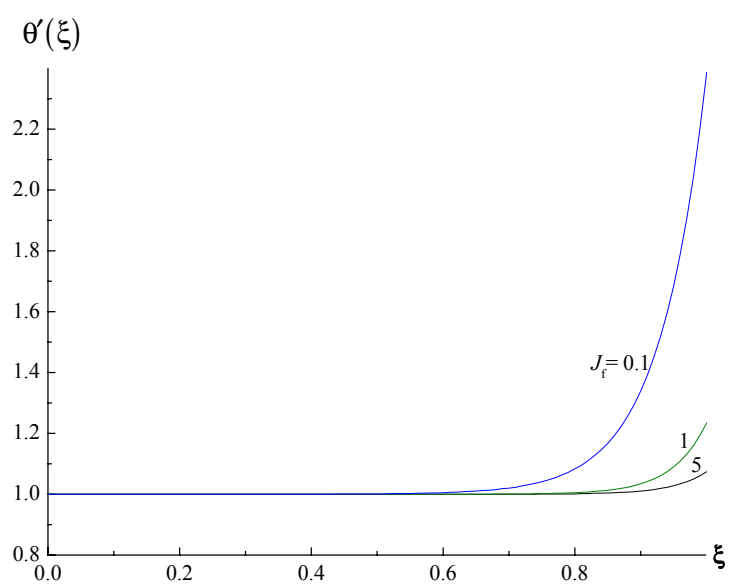

Figure 13. Temperature profile in the active thermal insulation $\left.d=0.01 \mathrm{~m} ; \delta=0.1 \mathrm{~m} ; \theta_{b}^{\prime}=3.74, J_{f} ; \mathrm{kg} /\left(\mathrm{m}^{2} \mathrm{c}\right)\right]$

\section{Thermal Mechanics of Active Thermal Insulation}

\subsection{Schemes of Figures 1a and 9}

The resistance of the infiltrated nonisothermal packed bed is calculated based on the solution of the Navier-Stokes equation for the heat carrier rate $V$ (Goldshtik, 1984):

$$
\rho_{f} V \frac{d V}{d x}=-\frac{d p}{d x}-\beta \rho_{f} V .
$$

The coefficient $\beta$ in the expression for the resistance force is taken in the form

$$
\beta=150 \frac{(1-\varepsilon)^{2}}{\varepsilon^{2}} \frac{\mu_{f}}{d^{2} \cdot \rho_{f}}+1.75 \frac{1-\varepsilon}{\varepsilon^{2}} \frac{u}{d}
$$

which in the isothermal case corresponds to the Ergun formula (Ergun, 1952).

Representing the resistance force in the form of the Ergun formula, the dependence of the dynamic viscosity of heat carrier and its density on temperature and pressure in the form $\mu_{f}=\mu_{f 0}\left(\theta^{\prime}\right)^{0.75}$ (Teplitskii, \& Kovenskii, 2011), $\rho_{f}=\rho_{f 0} p^{\prime} / \theta^{\prime}$, from (68) we have

$$
\frac{d \theta^{\prime}}{d \xi}=-\frac{\varepsilon^{2} E u}{2} \frac{d\left(p^{\prime}\right)^{2}}{d \xi}-\frac{\delta}{d}\left(150 \frac{(1-\varepsilon)^{2}}{\varepsilon} \frac{\left(\theta^{\prime}\right)^{1.75}}{R e_{0}}+1.75 \frac{1-\varepsilon}{\varepsilon} \theta^{\prime}\right)
$$

Integrating (70) with respect to $\xi$ going from 0 to 1 , we obtain the formula for calculation of the bed resistance:

$$
\frac{\Delta p}{p_{a t m}}=\sqrt{1+\frac{2}{\varepsilon^{2} E u}\left(I_{0}+\frac{1-\varepsilon}{\varepsilon} \frac{\delta}{d}\left(150 \frac{1-\varepsilon}{R e_{0}} I_{1}+1.75 I_{2}\right)\right)}-1
$$

where $I_{0}=\theta^{\prime}(1)-1 ; I_{1}=\int_{0}^{1}\left(\theta^{\prime}(\xi)\right)^{1.75} d \xi ; I_{2}=\int_{0}^{1} \theta^{\prime}(\xi) d \xi$. The function $\theta^{\prime}(\xi)$ is determined in (29).

As follows from (71), it allows for gas compressibility and bed nonisothermicity. We consider particular case of (71):

a) An isothermal bed $\left(I_{0}=0 ; I_{1}=I_{2}=1\right)$ : Equation (71) takes the form

$$
\frac{\Delta p_{T_{0}}}{p_{a t m}}=\sqrt{1+\frac{2(1-\varepsilon)}{\mathcal{E}^{3} E u} \frac{\delta}{d}\left(150 \frac{1-\varepsilon}{R e_{0}}+1.75\right)}-1
$$

b) Large values of $E u$ and small thicknesses of the bed $\delta$; Equation (72) is 


$$
\frac{\Delta p_{E}}{p_{\text {atm }}}=\frac{1-\varepsilon}{\mathcal{E}^{3} E u} \frac{\delta}{d}\left(150 \frac{1-\varepsilon}{R e_{0}}+1.75\right) .
$$

It is evident that (73) is the dimensionless presentation of the classical Ergun formula (Ergun, 1952):

$$
\frac{\Delta p_{E}}{\delta}=150 \frac{(1-\varepsilon)^{2}}{\varepsilon^{3}} \frac{\mu_{f 0} u}{d^{2}}+1.75 \frac{1-\varepsilon}{\varepsilon^{3}} \frac{\rho_{f 0} u^{2}}{d},
$$

which, probably, does not takes into account the gas compressibility.

\subsection{Schemes of Figures $1 b$ and $1 c$}

In this case, dependence (71) can also be applied if $\delta$ is replaced by $L$, but the functions $I_{0}, I_{1}$, and $I_{2}$ are determined by the formulas

$$
\begin{aligned}
& I_{0}=\int_{0}^{1} \bar{\theta}(\xi, \eta) \frac{T_{\infty}-T_{0}}{T_{0}} d \xi ; \\
& I_{1}=\int_{0}^{1} \int_{0}^{1}\left(\bar{\theta}(\xi, \eta) \frac{T_{\infty}-T_{0}}{T_{0}}+1\right) d \xi d \eta ; \\
& I_{2}=\int_{0}^{1} \int_{0}^{1}\left(\bar{\theta}(\xi, \eta) \frac{T_{\infty}-T_{0}}{T_{0}}+1\right) d \xi d \eta
\end{aligned}
$$

where the function $\bar{\theta}(\xi, \eta)$ is defined in (47).

Figure 14 presents the characteristic dependences $\frac{\Delta p}{\Delta p_{T_{0}}}\left(P e_{a c t}\right)$ that are built by (47), (71), (72), and (75) and show the influence of temperature on the packed bed resistance. The results of calculations are generalized in the form of the approximation formula

$$
\frac{\Delta p}{\Delta p_{T_{0}}}=1+0.35 P e_{a c t}{ }^{\left(-B i^{-0.1}+0.2\right)}\left(\frac{T_{\infty}-T_{0}}{T_{0}}\right)^{0.93} B i^{0.6},
$$

which is verified within the following ranges: $\left(1 \leq P e_{a c t} \leq 10 ; 0.2 \leq B i \leq 5.0 ; 1 \leq \frac{T_{\infty}-T_{0}}{T_{0}} \leq 5\right)$. The root-mean error is $10 \%$.

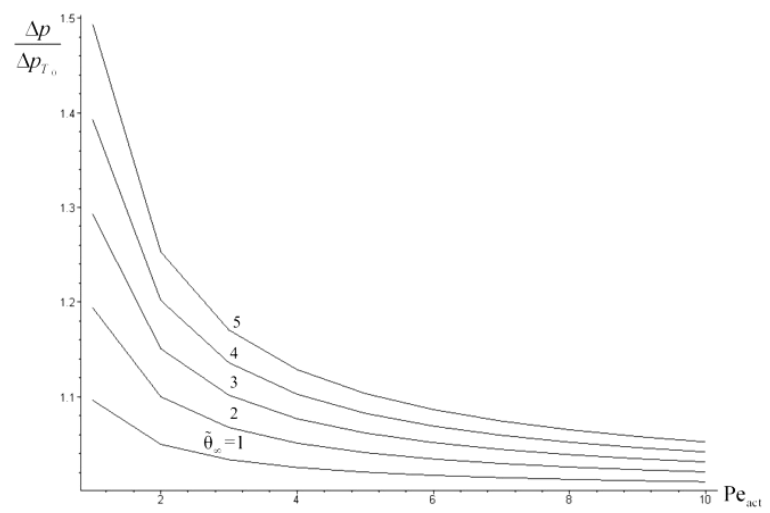

a)

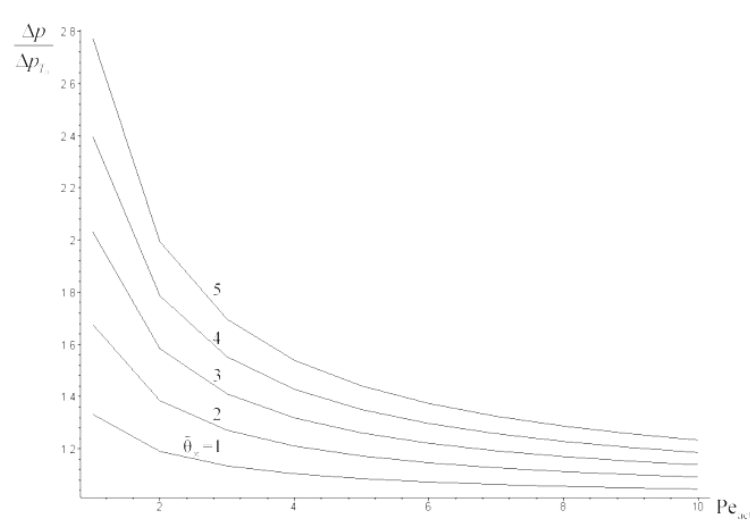

b)

Figure 14. Influence of temperature on the packed bed resistance: $a$ ) $B i=0.2 ; b) B i=1.0$ 


\section{Conclusions}

The processes of heat transfer in packed beds of large low-heat conducting particles used as active thermal insulation in different schemes of heat carrier motion have been studied. The criterion of active thermal insulation involving main geometric and thermal parameters of the packed bed is introduced. The effect of bed nonisothermicity and heat carrier compressibility on the thermal mechanics of the infiltrated packed bed is found. The approximation dependence of the resistance of the bed on its geometric, hydrodynamic, and thermophysical characteristics is obtained. Thermal conditions of the cap gas distributer with active thermal insulation are investigated by the method of successive approximations.

\section{References}

Aerov, M. E., Todes, O. M., \& Narinskii, D. A. (1979). Apparatuses with a Stationary Packed Bed. Leningrad: Khimiya.

Anonymous (1998). Thermal Calculation of Boilers (Standard Method). St. Petersburg.

Baskakov, A. P., Matsnev, V. V., \& Raspopov, I. V. (1996). Boilers and Furnaces with a Fluidized Bed. Moscow: Energoatomizdat. http://dx.doi.org/10.1016/S0017-9310(83)80032-5

Borodulya, V. A., \& Kovenskii, V. I. (1983). Radiative heat transfer between a fluidized bed and a surface. Int $J$ Heat Mass Transfer, 26(2), 277-87.

Dekhtyar, R. A., Sikovskii, D. F., Gorin, A. V., \& Mukhin, V. A. (2002). Heat transfer in a packed bed at moderate Reynolds numbers. Teflofiz Vys Temp, 40(5), 748-55.

Ergun, S. (1952). Fluid flow through packed columns. Chem Eng Progr, 48, 89-94.

Frank-Kamenetskii, D. A. (1967). Diffusion and Heat Transfer in Chemical Kinetics. Moscow: Nauka.

Goldshtik, M. A. (1984). Transfer Processes in a Packed Bed. Novosibirsk.

Kunii, D., \& Levenspiel, O. (1976). Fluidization Engineering. Moscow: Khimiya.

Luikov, A. V. (1967). Heat Conduction Theory. Moscow: Vysshaya Shkola.

Polezhaev, Yu. V., \& Selivestrov, E. M. (2002). Universal model of heat transfer in the systems with penetrating cooling. Teplofiz Vys Temp, 40(6), 922-930.

Polyaev, V. M., Maiorov, V. A., \& Vasil'ev, L. V. (1988). Hydrodynamics and Heat Transfer of Porous Elements of Structures of Flying Vehicles. Moscow: Machinery.

Teplitskii, Yu. S., \& Kovenskii, V. I. (2011). Transfer Process in a Heat Generating Packed Bed. Engineering Physics and Mechanics: Analyses, Prediction and Applications (Chapter 5, pp. 361-439).

Teplitskiy, Yu. S. (2002). Similarity of transport process in disperse systems with suspended particles. Int J Heat Mass Transfer, 45, 441-49. http://dx.doi.org/10.1016/S0017-9310(01)00162-4

\section{Nomenclature}

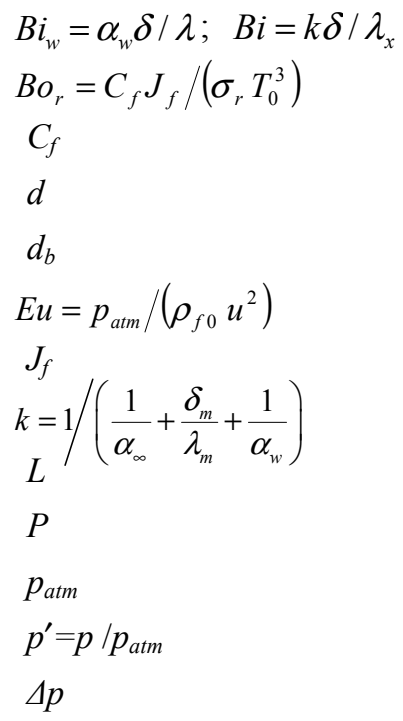

\author{
Biot numbers \\ reduced Boltzmann number \\ heat capacity of heat carrier $[\mathrm{J} /(\mathrm{kg} \mathrm{K})]$ \\ diameter of thermal insulation particles [m] \\ diameter of fluidized bed particles [m] \\ Euler number \\ mass flow rate of heat carrier $\left[\mathrm{kg} /\left(\mathrm{m}^{2} \mathrm{~s}\right)\right]$ \\ heat transfer coefficient $\left[\mathrm{W} /\left(\mathrm{m}^{2} \mathrm{~K}\right)\right]$ \\ packed bed length [m] \\ pressure $[\mathrm{Pa}]$ \\ atmospheric pressure $[\mathrm{Pa}]$ \\ pressure difference $[\mathrm{Pa}]$
}




$P e=C_{f} J_{f} \delta / \lambda$
$P e_{a c t}=C_{f} J_{f} \delta^{2} /\left(L \lambda_{x}\right)$
$P e_{f}=C_{f} J_{f} \delta /\left(\varepsilon \lambda_{f}\right), \quad P e_{s}=C_{f} J_{f} \delta /(1-$
$P r=C_{f} \mu_{f}^{0} / \lambda_{f}^{0}$
$R_{1}, R_{2}$
$R e=C_{f} J_{f} / \mu_{f}, R e_{0}=C_{f} J_{f} / \mu_{f}^{0}$
$S k=\sigma_{r} T_{0}^{3} \delta / \lambda$
$S t_{w}=\alpha_{w} /\left(C_{f} J_{f}\right), \quad S t_{0}=\alpha_{0} /\left(C_{f} J_{f}\right)$
$T$
$T_{0}$
$T_{b}$
$T_{m}$
$T_{s}, T_{f}$
$T_{w}$
$T_{w}^{*}$
$T_{\infty}$
$u$
$V=u / \varepsilon$
$x, y$

\section{Greek symbols}

$\alpha$

$\alpha_{0}$

$\alpha_{w}$

$\alpha_{\infty}$

$\delta$

$\delta_{m}$

$\delta_{m}^{*}$

$\varepsilon$

$\varepsilon_{s}$

$\varepsilon_{w}$

$\varepsilon_{e}$

$\lambda$

$\lambda_{f}$

$\lambda_{f}^{0}$

$\lambda_{s}$

$\lambda_{s}^{0}$

$\lambda_{m}, \lambda_{m}^{*}, \lambda_{x}, \lambda_{y}$
Peclet number

criterion of active thermal insulation

$\left((1-\varepsilon) \lambda_{s}\right), P e_{\alpha}=C_{f} J_{f} d /(6 \alpha(1-\varepsilon) \delta)$ Peclet numbers

Prandtl number

outer and inner radii of the bed $[\mathrm{m}]$

Reynolds number

Stark number

Stanton numbers

temperature $[\mathrm{K}]$

inlet temperature of heat carrier $[\mathrm{K}]$

fluidized bed temperature $[\mathrm{K}]$

temperature of lining $[\mathrm{K}]$

temperature of particles and heat carrier $[\mathrm{K}]$

temperature of the outer surface of the furnace $[\mathrm{K}]$

temperature of the gas-tight surface of the gas distributer directed to the fluidized bed $[\mathrm{K}]$

mean temperature in the furnace $[\mathrm{K}]$

superficial velocity $[\mathrm{m} / \mathrm{s}]$

transverse and longitudinal coordinates $[\mathrm{m}]$

coefficient of interphase heat transfer $\left[\mathrm{W} /\left(\mathrm{m}^{2} \mathrm{~K}\right)\right]$

heat transfer coefficient of the skeleton of particles $\left[\mathrm{W} /\left(\mathrm{m}^{2} \mathrm{~K}\right)\right]$

wall coefficient of heat transfer $\left[\mathrm{W} /\left(\mathrm{m}^{2} \mathrm{~K}\right)\right]$

coefficient of heat exchange between fuel gases and the wall of lining $\left[\mathrm{W} /\left(\mathrm{m}^{2} \mathrm{~K}\right)\right]$

packed bed thickness [m]

lining thickness [m]

thickness of the gas-tight plate [m]

porosity

emissivity of the particle material

emissivity of the furnace surface

packed bed emissivity

coefficient of effective longitudinal thermal conductivity of the bed $[\mathrm{W} /(\mathrm{m} \mathrm{K})]$

coefficient of effective thermal conductivity of the heat carrier $[\mathrm{W} /(\mathrm{m}$ $\mathrm{K})$ ]

coefficient of molecular thermal conductivity of the heat carrier $[\mathrm{W} /(\mathrm{m}$ $\mathrm{K})$ ]

coefficient of effective thermal conductivity of the particle skeleton $[\mathrm{W} /(\mathrm{m} \mathrm{K})]$

coefficient of thermal conductivity of the particle material $[\mathrm{W} /(\mathrm{m} \mathrm{K})]$

thermal conductivities $[\mathrm{W} /(\mathrm{m} \mathrm{K})]$ 


$$
\begin{aligned}
& \xi=x / \delta ; \\
& \rho_{f} \\
& \rho_{f}^{0} \\
& \bar{\theta}=\left(T-T_{0}\right) /\left(T_{\infty}-T_{0}\right) \\
& \theta^{\prime}=T / T_{0} \\
& \theta_{b}^{\prime}=T_{b} / T_{0} \\
& \theta_{f}^{\prime}=T_{f} / T_{0} \\
& \theta_{s}^{\prime}=T_{s} / T_{0} \\
& \theta_{f}-\left(T_{f}-T_{0}\right) /\left(T_{f}(\delta)-T_{0}\right) \\
& \theta_{s}=\left(T_{s}-T_{0}\right) /\left(T_{f}(\delta)-T_{0}\right) \\
& \theta_{w}^{\prime}=T_{w} / T_{0} \\
& \widetilde{\theta}=\left(T_{\infty}-T_{0}\right) / T_{0} \\
& \eta=y / L \\
& \sigma_{0}
\end{aligned}
$$

\section{Indices}

0

act

atm

$f$

m

$r$

$S$

$w$

$x$

$y$ heat carrier density $\left[\mathrm{kg} / \mathrm{m}^{3}\right]$

heat carrier density at atmospheric pressure and temperature $T_{0}\left[\mathrm{~kg} / \mathrm{m}^{3}\right]$
Stefan-Boltzmann constant $\left[\mathrm{W} /\left(\mathrm{m}^{2} \mathrm{~K}^{4}\right)\right]$
at the inlet
active
atmospheric
heat carrier
lining
reduced
particles
wall; furnace surface
transverse
longitudinal.

\section{Copyrights}

Copyright for this article is retained by the author(s), with first publication rights granted to the journal.

This is an open-access article distributed under the terms and conditions of the Creative Commons Attribution license (http://creativecommons.org/licenses/by/3.0/). 